\title{
Instilling Social Entrepreneurial Mindset through Transformative Learning
}

\author{
Karminder jit Singh, Anita Sharma, \\ LM Thapar School of Management, IIM Amritsar \\ Punjab, India
}

\begin{abstract}
The governmental interventions and the corporate-led development have not adequately addressed the wicked problems that the world faces today. Though social enterprises have demonstrated their ability to solve these complex problems, their role and size in the overall scheme of things are too small. This calls for developing a social entrepreneurial mindset (hereafter, SEM) in traditional professionals. However, the problem is the lack of a well-defined construct for SEM.

Building upon Transformative Learning Theory, this paper is a maiden attempt to establish and define the SEM as a multidimensional construct. A qualitative essay-based exploratory study, employing grounded theory approach was conducted on management graduates undergoing 'Sustainability in Practice' (an experiential project) compulsory course. The findings and analysis identify three main constituents of SEM, viz. prosocial orientation (compassion), entrepreneurial mindset (promotion focus, optimism, self-efficacy, proactiveness, and lowrisk aversion in uncertain conditions) and systemic change orientation.

The paper makes a theoretical contribution to the existing literature by proposing a comprehensive SEM framework as an overlap of prosocial orientation, entrepreneurial mindset, systemic change orientation dimensions. This framework can be of great value to both academicians for designing empirical studies to establish the causality as well as for practitioners for developing the best practices.
\end{abstract}

\section{Introduction}

As the world stares at existential crises in the form of environmental pollution, climate change, biodiversity degradation, widening of the gap between rich and poor; social entrepreneurship offers an innovative, creative model for building justice and sustainability [1]. However, the scale of the challenge is so humongous that select few social enterprises may not prove to be adequate. The solution might require equipping the corporate professionals with an SEM through academic interventions. The recent metaanalyses too have demonstrated the influence of dispositions on the behavior both in the corporate settings [2]. This leads us to a fundamental question, what constitutes a social entrepreneurial mindset?

Many scholars have explored 'entrepreneurial mindset' (EM) through different lenses: constituent, entrepreneurial process, and outcome perspectives. However, the debate is still on whether EM is cognitive or an essence. Few scholars, such as Krueger still argue that the literature explains meagrely about the composition of the EM and its dimensions. On the top of that, social entrepreneurship is still evolving as a discipline, and its theoretical underpinnings have not been adequately explored, and there is a pressing need for contributions to theory and practice. Consequently, to date, few studies have examined the domain of mindset concerning social entrepreneurship.

In order to develop SEM amongst its students the LM Thapar School of Management (LM TSM), Thapar University, Dera Bassi campus in India introduced a compulsory live project-based experiential learning course-Sustainability in Practice (SiP) in the MBA program. Building upon transformative learning theory, the present study makes a focused attempt to identify the constituents of SEM through this experiential education intervention.

As social entrepreneurship is gaining currency across the world; the identification of the constituents of SEM would enable the educational institutions and corporates to determine the extent of SEM amongst different individuals while making the selection decision.

\section{Theoretical underpinning}

Transformative learning involves perspective transformation, whereby one critically examines one's prior interpretations and assumptions [3]. Transformative learning transforms the frames of reference, which are "the structures of assumptions through which we understand our experiences. As these frames of reference selectively shape and delimit expectations, perceptions, cognition, and feelings" [3], there is a change in behaviors based on the transformation of the perspectives.

Thus, transformative learning is the expansion of consciousness through the transformation of the underlying worldview and specific capacities of the self. Though perspective transformation, which leads 
to transformative learning is usually caused by a "disorienting dilemma" triggered by a significant event or a series of events, the predicaments created by a teacher can also promote transformation [4].

\section{Literature review}

'Mindset' refers to the knowledge structures, which are anchored on the collection of thoughts and deep beliefs that accumulate and evolve through an iterative process and play a vital role in influencing how one makes sense of the world with which we interact.

Entrepreneurial mindset (EM) reflects deep beliefs and assumptions, which are manifested in the ability to rapidly sense, act and mobilize, even under uncertain conditions that enable individuals to capture the benefits of uncertainty [5]. There exist a sentiment that EM should be associated with entrepreneurial intentions, but EM indicates more about potential than intent. EM is vital to entrepreneurs and managers in established firms to think and act entrepreneurially.

Some scholars believe that social entrepreneurs are a type of entrepreneur rather than a separate category. Therefore, the characterization of the EM could apply to social entrepreneurship. However, there exists sufficient literature support that distinguishes how social and commercial entrepreneurs perceive and assess opportunities [6]. If the creation of sustainable social value differentiates social entrepreneur from individuals engaged in charitable works then the management of accountability, double bottom line, and the identity distinguish them from traditional entrepreneurs [7]. The difference is evident from the fact that many social entrepreneurs neither introduce themselves as "entrepreneurs" nor feel comfortable with that nomenclature when it is applied to them.

SEM actively seeks to identify and solve problems faced by impoverished communities in a sustainable manner. Social entrepreneurs empathize with marginalized people/creatures to pursue sustainability; they have an obsession to solve a systemic problem; apply systems thinking to tackle systemic issues; pursue the triple bottom line to achieve systemic change. As Dees [6] puts it, "Social entrepreneurs are one special breed of leader, and they should be recognized as such."

\section{Research method: Setting and sample design}

Social entrepreneurship domain is still in its nascent stage and our literature review suggested that SEM dimensions are not clearly established. Hence, we adopted the Grounded Theory approach to note and interpret the reality to bring natural emergence of theory to the systemic collection of data and analysis. As the SEM dimensions have not yet been explored, we employed a qualitative essay method [8] as it provides data, insights and research themes, which are not known beforehand. These essays offered the possibility to explore new insights and information about the dimensions or constituents of SEM through an experiential learning intervention amongst the MBA students of a management institute.

As a part of transformative learning, LM TSM introduced a compulsory live project-based experiential learning course-Sustainability in Practice (SiP) in the MBA program with an aim to develop an SEM, one of the program goals. For transforming the perspective of the students, they were expected to work in teams on projects that contribute towards social mission under the guidance of faculty mentors. A total of 160 students (MBA first year) aged 21 to 27 worked in 30 teams on sustainability-related projects, were approached and asked for voluntary participation in the study.

A total of 24 respondents participated in the study, wherein, all were given 60 minutes to write a qualitative essay on their experience and learning through this uniquely designed sustainability course. The collected qualitative data was processed and analyzed by practicing a grounded theory based data analysis and was compared and discussed by two researchers independently.

To conduct a proper data analysis process, we followed the constant comparative method [9]. We iteratively analyzed our essay data, moving back and forth between essays and the emergent categories. We adopted the four-step process comparing incidents applicable to each category; integrating categories and their properties; delimiting the theory; and writing the theory to generate theory.

\section{Findings and discussion: Dimensions of social entrepreneurial mindset}

Our understanding of the constituents of SEM viz., prosocial orientation, EM, and systemic change orientation presented in Figure 1 is explained in detail in this section through the following three main aspects:

\subsection{Prosocial Orientation}

Prosocial orientation has been related to decisionmaking for the creation of social enterprises, which hinges on the other-oriented emotion [10].

5.1.1. Compassion. With the exposure of the SiP program, students experienced the sufferings of others and experienced a desire to work towards the upliftment of lives of individuals.

[....]yes, in my thinking, larger perspective views come across to me to help people more and improve their lives (respondent 2).

[...]I feel very disturbed when hearing about pollution because the people who are living and work there, they have no option to go anywhere, and they are suffering a lot due to that (respondent 7). 
Compassion involving "being moved by another's suffering and wanting to help" is a prosocial motivator [11].

[...]I concern about the environment and would like to do whatever I can to aid in sustaining environment (Respondent 9).

Compassion is likely to characterize and drive social entrepreneurs to commit to their social mission [12] persistently. As compassion plays a crucial role in compelling individuals to alleviate others suffering, the compassion-driven cognitive ability may motivate certain individuals to exert more significant efforts in creating social enterprises [13].

\subsection{Entrepreneurial mindset}

EM as a metacognitive model and defined it as an ability to sense, act, and mobilize opportunities under uncertain conditions [14]. The various constituents of EM derived from the present study are as follows:

5.2.1. Promotion focus. The promotion self-regulatory focus triggers aspirational goals and forward-looking visions, i.e., a concern with advancement, growth, accomplishment [15].

In our study, many students explained their aspirational side. They want to excel and work to attain success in their lives.

[...]I want to do the best at what I do... I want to create a car company like Tesla (Respondent 17).

[...] I want to build a fair system to develop and deliver value for marginalized people (respondent 6).

This reflects a high need for achievement, which is positively related to entrepreneurial persistence and behavior [16].

[...] Initially, I did not appreciate the idea of having subject about sustainability. However, later on, when I underwent the course, I started to think- 'what' is 'that' which can improve the current situation and 'how' can I start doing it (respondent 20).

[...] I had joined an NGO which works for the betterment of society by distributing clothes to the poor and needy people (respondent 7).

These statements by the student suggest that promotion focus positively influences the appreciation of novel information, which should enhance opportunity recognition [17].

5.2.2. Optimism. It was evident from the data that students while going through engaging projects developed optimism through $\mathrm{SiP}$ program. Optimistic outlook creates risk takers who underestimate the odds they face [18].

[...] I am an intrinsically motivated person and see the positive side of everything (Respondent 8).

Literature also suggests that entrepreneurs were found more likely to be optimistic than the people with similar demographic, financial, and educational backgrounds [19]. It enhances the likelihood of identifying creative solutions by altering imagination and increasing positive affect; induces overconfidence in the ability to successfully implement these solutions, which enhances the possibility of entering the market [20].

[...]I feel happy, and that happiness transcends me to another world of love......... happiness is serving others (respondent 1).

[...] sometimes things are not the way we want it. But, we need to keep going and perform (Respondent 14).

Our results also suggest that optimistic people are happier, experience more positive affect [21] and these positive emotions encourage people to try new things by widening the attentional focus [22].

5.2.3 Self-efficacy. Self-efficacy, the belief in one's capabilities to organize and execute the actions required to manage prospective situations is an essential antecedent to entrepreneurial action [23]. This is because of the fact that an individual's perceptions of their skill can be more important in determining behavior than the objective skills [24].

[...] Emotional connectivity with people who are needy and also the love for nature makes me feel that I have the ability to lead an initiative because I feel if in anything no matter what if the soul is involved success is guaranteed (respondent 2).

Influenced by the past performance, self-efficacy is an essential precondition to support and successfully enact the EM [25].

[...] Sip course is purely helping me in developing and inculcating social and entrepreneurial mindset and skills to behave in an entrepreneurial way (Respondent 24).

Self-efficacy is connected to opportunity recognition and the decision to pursue an entrepreneurial career [26].

Many students in our analysis mentioned their ability to initiate something. For instance:

[...] I plan the blueprint of the task and work on it until it gets over (Respondent 14).

[...] I am doing activities to be a part of to protect people, animals, and the environment. Thus having a sense that I can initiate (Respondent 18).

Hence, our findings substantiate that students have developed a certain level of self-efficacy and readiness to work towards sustainability (people and environment).

As higher level of entrepreneurial self-efficacy is related intentions to start a new venture, it is an important antecedent to entrepreneurial action [27].

5.2.4. Proactiveness. Many of our respondents reflected the proactive behavior in their essay.

[...] I want to start my own business which will run only for pet animals and their better living (Respondent 12).

Hence, they wish to explore opportunities, have a forward-looking perspective which involves introducing new products before their competitors and 
taking actions in anticipation of the future demand to create change and shape the environment [28].

A proactive personality in relative terms is not constrained by the situation and causes environmental change.

[...] Before joining the program, I had a very careless attitude. Never thought of water and electricity wastage. After the SiP course, I know that how wrong I was. I was not protecting it for coming generations......But now, I need to aware others about wastage (Respondent 5).

This proactiveness plays a central role in the EM by connecting personal action to the future goal and operationalizing the grit and persistence for its attainment because it makes the entrepreneurs believe that their future is up to them and they can create the future for themselves [29].

\subsubsection{Lower risk aversion in uncertain conditions.}

[...] Sometimes Yes, Sometimes No. And if I take a risk, I won't say it is a bold act by me[...] (respondent 10).

It was evident from the data that students reflected aspects of risk-taking.

[...] I feel good when I face uncertainty because my effort is to give my best in that situation (Respondent 19).

The SiP program was able to make more risk tolerant. As also explored in the literature that the tolerance for risk is one's general degree of comfort with facing uncertain gains or losses. Students persistently reflected this aspect in their actions.

[...] Risk is the first step to explore any opportunity (Respondent 13).

[...] As an entrepreneur, I would definitely like to take a risk to satiate my hunger to work for needy people around me (respondent 10).

Above statements substantiate that student's attitude toward risk, a crucial variable explaining their motivation to become self-employed [30] was influenced through this experiential course.

\subsection{Systemic change orientation}

The systems thinking mindset needs to be applied to conceptualizing reality regarding the complex world for making better decisions to address these fundamental problems [31].

Students experienced real-time problems through their $\mathrm{SiP}$ projects.

[...] I think that the through the experience of SiP projects I became a better human being who now feels for the welfare of all in future (Respondent 11).

[...] I want to work for Tesla or SpaceX like companies, or otherwise want to create something similar because they value innovation and human values and act in a sustainable manner (Respondent 23).
[...] Ignited minds ignite others, it can be done through a co-creating space between different organizations (Respondent 21).

Respondents views represent that they are willing to bring some changes. It is defined consistently as fundamental, sustainable, and large-scale change. It is bringing about lasting change in the status quo by shifting the function or by altering underlying structures and supporting mechanisms of an identified system with purposeful interventions [32].

It provoked my thinking...Now I would like to see my life objection to make people happy[...] and wish to contribute towards societal upliftment even in a problematic situation (Respondent 3 ).

I have always thought of working for society and perceived it as my moral duty/ obligation. The SiP course reinforced my thoughts on serving the community and giving back to the environment (Respondent 5).

The above statements are clear indications of students' way of thinking towards change making behavior. The literature on social entrepreneurship also reflects that social entrepreneur's core is 'changemaker' who strive to create self-sustainable projects for social benefits.

\section{Discussion and Implication}

Our study is an attempt to explicate the dimensions of social entrepreneurial mindset. Figure 1 suggests that Social Entrepreneurial Mindset is a cognitive phenomenon that exists and is operationalized at the overlap of prosocial orientation, entrepreneurial mindset, and systemic change orientation.

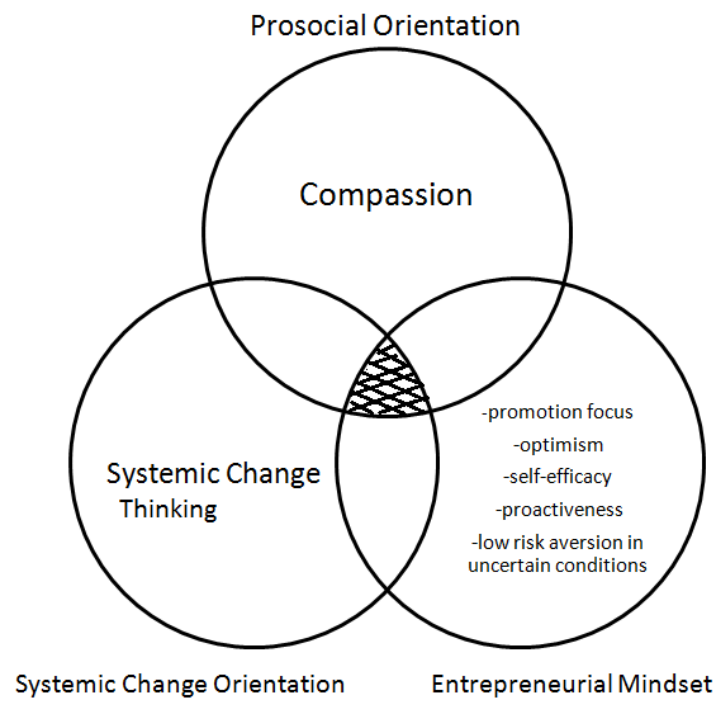

Figure 1. Social Entrepreneurial Mindset Framework

The implication for Theory: The present study contributes to existing literature in two ways. First, it operationalizes SEM as a multidimensional construct 
constituting three clusters, one comprising of prosocial orientation (viz. compassion), the second cluster containing different aspects of entrepreneurial mindset (i.e. promotion focus, optimism, self-efficacy, proactiveness, lower risk aversion in uncertain situations) and third comprising of orientation to bring in systemic change and. We propose that SEM exists at the interface/overlap of these clusters. Moreover, second, our work extends the social entrepreneurship literature towards the domain of underlying cognitive phenomenon, i.e., mindset.

The implication for practice: The identification of dimensions of SEM would enable the responsible corporates to identify and recruit employees with social entrepreneurial mindset.

\section{Conclusion}

This research is a preliminary endeavor to define and determine the dimensions of the SEM, which is yet to be established as a construct in the literature. Through our framework, we have endeavored to highlight the constituents of SEM such as prosocial orientation, EM, and systemic change orientation.

Our framework can guide further studies that need to be conducted to operationalize and examine the causality between the antecedents and consequences and contribute towards the development of models regarding SEM in various situational factors.

\section{References}

[1] Stenn, T. Social Entrepreneurship as Sustainable Development: Introducing the Sustainability Lens, Palgrave Macmillan, 2017.

[2] Barrick, M.R., and M.K. Mount, "The Big Five Personality Dimensions and Job Performance: A MetaAnalysis", Personnel Psychology; Spring, 44, 1991, pp. 126.

[3] Mezirow, J. "Transformative Learning: Theory to Practice", New Directions for Adult and Continuing Education, Issue 74, Summer 1997, pp. 5-12.

[4] Torosyan, R. Teaching for Transformation: Integrative Learning, Consciousness Development and Critical Reflection. 2007. http://www.faculty.fairfield.edu/rtorosyan/

[5] McGrath, R.G. and I. MacMillan, The Entrepreneurial Mindset: Strategies for Continuously Creating Opportunity in an Age of Uncertainty, Boston: Harvard Business School Press, 2000

[6] Dees, J.G. "The Meaning of "Social Entrepreneurship"”, https://entrepreneurship.duke.edu/news-item/the-meaning-ofsocial-entrepreneurship/, 2001.

[7] Tracey, P., and N. Phillips, “The Distinctive Challenge of Educating Social Entrepreneurs: A Postscript and Rejoinder to the Special Issue on Entrepreneurship Education", Academy oi Management Learning and Education, 6: 2007. pp. 264-271.
[8] Hartley, J., and K. Chesworth, "Qualitative and Quantitative Methods in Research on Essay Writing: No One Way", Journal of Further and Higher Education, 24, 2000, pp. $15-24$.

[9] Glaser, B.G., and A. Strauss Discovery of Grounded Theory. Strategies for Qualitative Research, Sociology Press, 1967.

[10] Dees, J. G. “Taking social entrepreneurship seriously”, Society, 44, 2007, pp. 24-31.

[11] Lazarus, R.S., Emotion and Adaptation, Oxford, England: Oxford University Press, 1991.

[12] Grant, A.M., J.E. Dutton, and B. Rosso, "Giving commitment: Employee Support Programs and the Prosocial Sensemaking Process", Academy of Management Journal, 51, 2008, pp. 898-918.

[13] Moon, C.W., and Y.S. Koh, "Compassion, Pro-social Motivation and Social Entrepreneurship: An Empirical Investigation", Proceedings of the Third Asia-Pacific Conference on Global Business, Economics, Finance and Banking (AP15Singapore Conference), July 2015.

[14] Ireland, R., Hitt, M. and Sirmon, D. "A model of strategic entrepreneurship: the construct and its dimensions", Journal of Management 29(6), 2003, pp. 963-989.

[15] Higgins, E.T., "Beyond Pleasure and Pain", American Psychologist 52(12), 1997, pp. 1280-1300.

[16] Collins, C.J., P.J. Hanges, and E.A. Locke, The Relationship of Achievement Motivation to Entrepreneurial Behavior: A 2004. http://digitalcommons.ilr.cornell.edu/cgi/viewcontent.cgi?arti cle $=1841 \&$ context $=$ articles .

[17] Kark, R., and D. van Dijk "Motivation to Lead, Motivation to Follow: The Role of the Self-Regulatory Focus in Leadership Processes," Academy of Management Review 32(2), 2007, pp. 500-528.

[18] Kahneman, D. Thinking Fast and Slow, Farrar, Straus, and Giroux, New York, 2011

[19] Puri, M. and D.T. Robinson, "The Economic Psychology of Entrepreneurship and Family Business", Journal of Economics \& Management Strategy, 22(2), 2013, 423-444.

[20] Kappes, A. and T. Sharot, "Optimism and Entrepreneurship a Double-Edged Sword", 2015, http://affectivebrain.com/wpcontent/uploads/2015/05/optimism_and_entrepreneurship__a_double-edged_sword.pdf.

[21] Carver, C.S., M.F. Scheier, and S.C. Segerstrom, "Optimism", Clinical Psychology Review. 30(7), 2010, pp. 879-889.

[22] Hayward, M.L.A., W.R. Forster, S.D. Sarasvathy, and B.L. Fredrickson, "Beyond hubris: How highly confident entrepreneurs rebound to venture again", Journal of Business Venturing, 25(6), 2010, pp. 569-578. 
[23] Zhao, H., S.E. Seibert, and G.E. Hills, "The Mediating Role of Self-Efficacy in the Development of Entrepreneurial Intentions", Journal of Applied Psychology, 90(6), 2005, pp. 1265-1272.

[24] Krueger, N.F., and P.R. Dickson, "How Believing in Ourselves Increases Risk Taking: Perceived Self-Efficacy and Opportunity Recognition", Decision Sciences 25(3): June 2007, pp. 385-400.

[25] Mauer, R., H. Neergaard, and A. Kirketerp Linstad, "Self Efficacy: Conditioning the Entrepreneurial Mindset", International Studies in Entrepreneurship, 24, 2009, pp. 233257.

[26] Kickul, J., L.K. Gundry, S.D. Barbosa, L. Whitcanack, "Intuition Versus Analysis? Testing Differential Models of Cognitive Style on Entrepreneurial Self-Efficacy and the New Venture Creation Process", Entrepreneurship Theory and Practice, 33(2), Mar 2009, pp. 439-453.

[27] Boyd, N.G., and G.S. Vozikis, "The Influence of Selfefficacy on the Development of Entrepreneurial Intentions and Actions", Entrepreneurship Theory and Practice, 18(4), 1994, pp. 63-77.

[28] Lumpkin, G.T., and G.G. Dess, "Linking Two Dimensions of Entrepreneurial Orientation to Firm Performance: The Moderating Role of Environment and Industry Life Cycle", Journal of Business Venturing, 16 (5), 2001, pp. 429-451.

[29] Rosen, A., "Why Future Orientation ts the Most Important Part of Entrepreneurial Thinking", 2016, https://www.entrepreneur.com/article/254921.

[30] Douglas, E.J., and D.A. Shepherd, "Entrepreneurship as a Utility Maximizing Response", Journal of Business Venturing, 15(3), 2000, pp. 231-251.

[31] Checkland, P. "Four conditions for serious systems thinking and action", Systems Research and Behavioral Science 29(5), 2012, pp. 465-469.

[32] Abercrombie, E.H., and R. Wharton, Systems Change a Guide to What it is and How to do it, New Philanthropy Capital (NPC), June 2015. 